\title{
Green infrastructure practices - strategies how to sustain life in metropolitan areas
}

\author{
Anna Zaręba1,a, Alicja Krzemińska1 ${ }^{1}$, Krzysztof Widawski ${ }^{1}$ and Piotr Oleśniewicz² \\ ${ }^{1}$ University of Wrocław, pl. Uniwersytecki 1, 50-137 Wrocław, Poland \\ ${ }^{2}$ University School of Physical Education in Wroclaw, Banacha 11, 51-617 Wrocław, Poland
}

\begin{abstract}
Green Infrastructure is 'an interconnected network of green space that conserves natural ecosystem values and functions and provides associated benefits to human populations' [1, p. 12]. It contributes to long term strategic development goals for data and information management. The research paper was introduced with the aim to protect green areas in urban environment by improving biodiversity, leisure and recreation, tidal and fluvial flood risk management, grey water treatment and quality of life. Planning and design of green system should provide appropriate responses to the distinctive local circumstances. Green spaces encourage social interactions, form new places to practise sport and contribute to public health and fitness, as well as have indirect benefits for a range of environmental services. The research hypothesis is that Green Infrastructure is a framework for conservation and development and we need to design Green Infrastructure systems strategically to connect across urban, suburban, rural and wilderness landscapes and incorporate green space elements and functions at the state, regional, community, neighbourhood and site scales [2]. Analysis and design of emerging Green Infrastructure system take a holistic view which links related physical, environmental, economic, social and cultural aspects of local communities.
\end{abstract}

\section{Introduction}

Intensive urbanization hampers the development and quality of municipal green areas, new terrain is covered by newly erected structures, pollutionincreases, forest area is reduced, erosion intensifies, biodiversity decreases due to fragmentation of habitats. The ecological functioning of green areas is largely dependent on the size of plant clusters, immunity, ecological relations, durability and use. As important as their role may be, urban ecosystems are, nevertheless, increasingly at risk of being devastated by an ever-expanding city. Planning solutions within the framework of Green Infrastructure are of extraordinary importance in urban environment as it is inhabited by over $60 \%$ of the EU population. Green Infrastructure in cities may have a beneficial effect on general health in the form of clean air, better quality water and wider accessibility of recreational grounds.

\section{Objectives of the research}

The main goals of the paper are: to identify opportunities for the restoration and enhancement of naturally functioning systems in already developed areas, to provide mechanism to identify green areas used for multiple functions: including ecological, recreational, cultural, aesthetic and other uses. The task of the paper is to present models of the Green Infrastructure strategy construction using various examples of metropolitan areas as case studies. The basic idea is to make comparison between Green Infrastructure practices and to create the review of scientific analysis of the GI typology and assessment which in further practical research could be used to develop urban planning models flexible enough to accommodate new development, but at the same time constant in protecting valuable terrain for recreation and the environment. The idea is to introduce the Green Infrastructure examples, which could be applied in different spatial settings.

The question is how to change municipal industrial and residential areas to fulfil different expectations of the inhabitants and optimize the use of accessible land for multiple functions related to polycentric city-regions recreation, water management, health, biodiversity, renewable energy, sustainable transport, etc. The idea of the paper is to introduce models of ecological integrity which will help in regeneration of the environment and reclamation of derelict landscapes in cities. This paper takes a new approach to framing the role of green spaces within a multifunctional Green Infrastructure, and to developing a scientific analysis which promote spatial integration, sustainable transport, health and accessibility. Traditional land conservation and green infrastructure planning both focus on environmental restoration and preservation, but Green Infrastructure also concentrates on the pace, shape, and location of development and its relationship to important natural resources and amenities.

\footnotetext{
a Corresponding author: anna.zareba $@$ uwr.edu.pl
} 


\section{From Urban Ecological Network to Green Infrastructure}

Urban Ecological Networks concept introduced at the end of 20th century to connect green network and green structure concepts can be defined as: protecting or enhancing natural resources and systems while linking the urban area for recreation use [3]. The idea gives possibility to integrate of urban areas into a structural network as legally recognised instrument of planning in different scales (from regional to city and habitat). The principles of the concept were used in developing of Pan European Network for Central and Eastern Europe as well as in the "Green Hand" Copenhagen idea. Design features combine: ecological, recreation, cultural and aesthetes functions. The Ecological Network, was introduced with the aim to maintain the integrity of environmental processes by promotion of sustainable use of natural resources in order to reduce the impacts of human activities on biodiversity and/or to increase the biodiversity value of man-aged landscapes [4,2]. This system include vital ecological components: core areas (hubs), corridors, mix land used buffer zones (transitional areas) and sustainable-use areas. In the USA planning the Urban Ecological concept influenced the beginning of "greenways" idea, which corresponds to question how to create the large scale combination of green and blue ways connecting city, suburbs, exurbs and hinterland. Greenways, in the concept, are networks of land including linear elements that are planned for multiple purposes as: ecological, recreation, cultural, aesthetic, or other [5]. Greenways are multi-objective corridors, which have a key meaning in maintaining biodiversity, urban flood damage reduction, enhancing water quality and wildlife protection. The modern US greenways combine various landscape ecology features (examples: corridors, patches, matrix). Multi-function Rose Kennedy Urban Greenway, opened to the public in 2008, joins the park and public spaces in downtown of Boston.

Green infrastructure is a relatively new term in urban planning. It was used for the first time in 1994 report on land conservation strategies by the Florida Greenways Commission. Introduced initially as a new way of looking at nature conservation, with intent to elevate the value and functions of natural lands to the same level of importance as roads, constitute "grey infrastructure", assumed the proportion of the most important tool of sustainable development. In spatial planning across the EU the term Green Infrastructure (GI) corresponds to planning and management of green networks of multifunctional open spaces in a way that allows to support biodiversity and quality of life of inhabitants, particularly in derelict lands. Its design and management should also respect and enhance the character and distinctiveness of an area with regard to habitats and landscape types. Natural England defines Green Infrastructure as: "a strategically planned and delivered network comprising the broadest range of high quality green spaces and other environmental features. It should be designed and managed as a multifunctional resource capable of delivering those ecological services and quality of life benefits required by the communities it serves and needed to underpin sustainability..." $[6,7]$. The GI combines: parks and gardens, natural and semi-natural urban greenspaces - including woodlands, wetlands, open and running water, green and blue corridors, outdoor sport facilities, amenity greenspaces, allotments, community gardens, urban farms, green roofs and walls. In the US spatial planning apart from the above mentioned comprehensive view about the significance of green areas, according the guidelines of the United States Environmental Protection Agency, Green Infrastructure strategies should first of all draw attention to problems of reduction or divert water from the sewer system though infiltration, re-usage and evapotranspiration. Green infrastructure refers to "systems and practices that use or mimic natural processes to infiltrate, evapotranspiration (the return of water to the atmosphere either through evaporation or by plants), or reuse storm water or runoff on the site where it is generated [7,8].

Green Infrastructure is a combination of interconnected hubs of nature lands. Hubs, including reserves, managed native landscapes, working lands, regional parks and preserves, community parks and natural areas differ in shapes and sizes. The continuity of that green network is possible thanks to system of linkages: landscape linkages, conservation corridors, greenways, green corridors, ecobelts [9]. Green Infrastructure technics include storm water infrastructure, tree planting, ecological restoration, green building and green roofs. Storm water infrastructure allows to direct runoff to areas that retain and infiltrate water through bioswales (natural drainage ways implemented to receive and absorb runoff), wetlands, rain gardens (vegetation planted in natural or artificial depressions) and permeable surfaces). Planting of trees as the basic technic of GI can be implemented in different scales: from single parcel to neighbourhood, boulevards, ecological corridors and regional parks. GI application in ecological restoration include among other things: renaturation of river valleys, replanting of native vegetation and removal of invasive species.

Green Infrastructure delivers a broad range of benefits to environment which can be grouped in three categories: environmental, economic and social. This multiscale benefits are particularly visible in highly damaged and limited urban environment. GI benefits include:

- reduced storm water runoff volumes - through usage of natural retention and absorption capabilities of vegetation

- enhance groundwater recharge - through implementation of natural infiltration of GI technologies

- improving environment quality - storm water pollutant reduction and absorption pollutants from the air through leaf uptake and contact removal

- reduced sewer overflow events - through usage of natural retention and absorption capabilities of vegetation allows to reduce runoff volumes and delay storm water discharges

- mitigation of Urban Heat Island Effect - implementation of trees, green roofs, green walls, permeable pavements can help in decreasing temperature in city centres and reduce demand for energy for air conditioning and heating 
- increase biodiversity

- additional recreational space - new parks, urban forests, wetlands, greenways, boulevards and other forms of Green Infrastructure create accessible recreational space for city inhabitants

- improved human health and wellbeing - GI has positive impact on local communities

- increased land values in surrounding residential areas [7].

\section{Multi-function of green infrastructure in regeneration of metropolitan areas - case studies}

Theory of patchiness in landscape ecology allows to understand dynamics in urban ecosystem expressed in the flow of energy, matter and species across the countryside. It gives the tools to explain spatial heterogeneity and multi-scale of Green Infrastructure seen as a bond between different forms of urban continuum: city, inner suburbs, suburbs, exurbs and hinterland divided further into land use types, neighbourhoods, blocs, etc. [10]. In other words Green Infrastructure as a system consists of parts (ex. trees, soil, infrastructure etc.) that are organized in patterns (green core areas, green corridors) and performs various functions (ex. climate mitigation, recreation, environmental protection etc.). Green Infrastructure is subjected to hierarchy rules: 'it incorporates multiple subsystems (e.g., hydrology, vegetation, and movement) and in turn is a subsystem within a larger system (e.g., region, city, or neighbourhood), where it interacts with other systems (e.g., transportation, economy, and governance)' [8].The contemporary Green Infrastructure concepts put emphasis on multi-purpose usage of green areas. Metropolitan regions that effectively incorporate greenspace and Green Infrastructure into their urban fabric use natural areas not only for maintaining and enhancing biodiversity and habitat conservation but also in innovative storm water management, recreation, sustainable food production and delivery systems.

\subsection{The Emerald Necklace Expanded Vision Plan (2014)}

In the 1930 the Los Angeles Chamber of Commerce concerned at the growing air pollution, overpopulation and the lack of inner city green areas introduced the repair plan for the future - The Emerald Necklace, completed by the famous urban park pioneer Frederick Law Olmsted, Sr. The plan, rooted in the "emerald necklace" vision for Boston. designed in the late 1800's wasn't adopted and during last decades the urbanization sprawled dramatically. In 2005 the vision plan was significantly extended to connect 17-mile loop of parks and greenways along the Río Hondo and San Gabriel Rivers in eastern Los Angeles, inhabited by nearly 500,000 residents. The guidelines for the Plan included: restoration of the Los Angeles and San Gabriel rivers and tributaries for recreational open space, conservation of native habitat, and put emphasis on education. After three years the necessity of unification of heavy overpopulated area of Southern California assumed the proportion of the most important planning goal and The Emerald Necklace Expanded Vision Plan to connect 1,500 acres of parks and open spaces along an greenways around the Río Hondo, San Gabriel, and the lower Los Angeles Rivers was initiated. The planning target is to link Los Angeles County with interconnected multi-purpose network of parks, rivers and land [11].

\subsection{Trinity River Corridor Project}

The Trinity River Corridor Project of converting the 2,300-acre floodway of the Trinity River near downtown Dallas to a sustainable Green Infrastructure joins flood control, environment, recreation, transportation, and economic development actions. The project key concept apart from regeneration of the downtown and increasing the level of green amenity areas, is to modify existing levees to achieve sustainable flood protection by introducing recreational lakes (built on the place of extraction of materials needed for construction of new roads), marshlands, wetlands which help to maintain water cleansing, aquatic habitat, and recreational value. Green corridors are perfect examples to illustrate a rule of interconnectivity of watercourses linking rural, suburban, and urban areas within a region, introduced for multi-function providing multiple benefits for communities. The scale of actions could vary from typical urban investments, less managed landscape in suburbs to riparian woodland in rural area [12].

\subsection{The Regional Plan of Territorial Planning in the Metropolitan Area of Lisbon (2010)}

The plan was introduced with the idea to incorporate existing and new green urban areas into regional spatial planning. The Metropolitan Ecological Network (Rede Ecológica Metropolitana, REM) was established to coordinate a network of green areas between cities and with the urban system The objectives of the Metropolitan Ecological Network (Rede Ecológica Metropolitana, REM) are to maintain and enhance ecological connectivity. The plan is orientated not only to ecological goals as: revitalization of degraded urban areas, renaturalisation of watercourses, prevention and reduction of natural risks and protection of water resources, soil and landscape in urban environment, but also to society benefits as: tourism, recreation and leisure. Green areas in REM were organized on three hierarchical levels according to their contribution to the ecological structure of the metropolitan area (Rede Primária, Rede Secundária e Rede Complementar) [13].

\section{Green Infrastructure practices - how to build healthier environment and sustainable communities}

Green Infrastructure solutions can be applied at different scales (regional, local, subarea, district, neighborhood and site) and in different contexts. At the regional level implementation of Green Infrastructure guidelines can help in urban revitalization and landscape preservation (e.g. in maintaining and enhancing watersheds, ecological zones), at the scale of local government in maintaining the continuity of green areas in urban and suburban zones (e.g. through greenways), at the district and neighborhood in 
delivering of new amenity space in master planning and urban design. The benefits of implementation of GI solutions at the site scale concern green storm water infrastructure, green roofs, green walls, etc.

\subsection{Data Inventory}

The data include information about: geographical environment (e.g. division of administrative units, water pattern, slopes, settlement pattern, transport network), nature base (e.g. biotopes, designated areas, natural vegetation areas), land base (e.g. soil type, land quality, soil erosion sites, land cover) and water resources.

\subsection{Defining the Green Infrastructure Network}

A Green Infrastructure network map illustrates long-term planning pattern of GI areas and shows their relation to other components of the community's spatial guidelines. The map is the result of data inventory with distribution of existing and potential Green Infrastructure. The guidelines how to create the GI Network are included in Chapter: Smart Growth \& Smart Conservation in the State of Maryland of Benedict and McMahon book [9] describing a comprehensive approach to designing the GI, which was used in Maryland and Florida in 1997. According to Benedict and McMahon, natural ecosystem values and functions are primary criteria to identify network components. The methodology uses the largest, highest-quality areas of natural habitat and the most important ecological links, which bond together GI patches. In Maryland's Green Infrastructure Assessment, the minimum size of defined hubs is 250 acres and links 1,100 feet in width. The Maryland GIA used GIS methods to identify high priority lands, for example: the series of watershed maps was created as the result of analysis of data layers e.g.: natural vegetation types, stream systems and topographic features. The methodology prioritize conservation targets and preservation of the most important hubs of natural areas introduced for multiple ecological benefits (e.g., water quality protection, biodiversity, conservation and restoration of natural areas) $[14,8]$. The hubs and corridors were marked through consideration of factors: land cover, wetlands, sensitive species, roads, terrestrial and aquatic conditions, floodplains, soils and development pressure. After the identification of hubs and corridors GIS methods were used to assess the network's components for vulnerability to development. Further analysis included consideration of ecological value of components. The ultimate comprehensive map showed composite ranking of components according to ecological value, vulnerability to growth and current degree of protection. The task of ranking was to recommend the areas that should be at the top of the state's acquisition list [14].

Above mentioned approach to Green Infrastructure can easilybe applied in the area of intact natural resource land. In urbanized, highly fragmented environment looking only for the largest areas of virgin nature seems irrelevant. Investigation on planning models should be based on GI classification : agricultural land, allotment, community garden or urban farm, cemetery, churchyard or burial ground, derelict land, general amenity space, grassland, heathland, green roof, institutional grounds, orchard, outdoor sports facility, park or public garden, private domestic garden, street trees, water body, water course, wetland, woodland, green corridors, (not GI) etc. and attributing green areas to functions such as: habitat for wildlife, corridor for wildlife, soil stabilization, water supply, wind shelter, recreation, learning, etc. Each GI element can perform multiple functions, for example: green travel route, aesthetic, shading from sun, noise absorption, habitat for wildlife, corridor for wildlife, soil stabilization, water supply, wind shelter learning. Using the smallest possible units of functionality allows a distinction to be made between GI elements, but also provides a platform for grouping functions (eg. into benefits) at a later date. In the next step of GI strategy guideline needs for particular functions are assessed which allows to introduce the Intervention Plan. This method has been developed by the North West Green Infrastructure Unit for mapping Green Infrastructure. North West Green Infrastructure Guide consists of five steps: Partnership and Priorities, Data Audit\& Resource Mapping, Functionality Assessment, Needs Assessment and Intervention Plan [15].

Allen [16] established a straightforward set of GI project typologies that are organized into three categories: 1) Income Generating (urban forest, commercial harvesting, urban agriculture, food production in re-used buildings, alternative energy, 2) Compliance/Regulatory (stream/riparian restoration, storm water park phytoremediation (i.e. plantings to Sunflower planting for toxics absorption mitigate contamination without excavation) impervious surface reduction, and 3) Community Benefit (local recreation facilities, recreational trail linkages, non-production garden, community garden).

\subsection{Plan Goals and Policies}

GI plans include goals which define the vision that a community would like to achieve, objectives how to achieve the planned out goals, policies to guide decision making and implementation strategies and actions. Comprehensive plans involve Green Infrastructure solutions in community systems (community facilities and services, etc.), for example green boulevards, belts of trees along rivers can incorporate gray infrastructure: pedestrian, bicycle and car roads into native plantings and natural storm water management features [8]. Policy priorities identified by Natural Economy North West, a partnership between Natural England and the North West Development Agency represent 11 benefits of Green Infrastructure 'interventions' grouped in 3 categories economic (economic growth and employment), environmental (protect and enhance cultural heritage, protect and enhance the landscape, geodiversity and natural environment, biodiversity conservation and enhancement, climate change mitigation and adaptation and social (promoting sustainable transport and reducing the need to travel by car, community cohesion and lifelong learning; volunteering, healthy communities; health and wellbeing) [17]. 


\subsection{Implementation and Monitoring}

Plans include an implementation program that establishes action priorities, timelines, and indicators of progress. Green infrastructure implementation tools are grouped in four main categories: land dedication, regulations, incentives, and physical investments [8].

\section{Conclusions}

Natural environmental qualities are a significant value in spatial management. In many metropolitan areas, green space is rapidly disappearing. Preservation of urban greenery is the underlying principle of metropolitan regions eco-development. Identification and evaluation of green areas is one of the rationales behind spatial management. Absence of information on the potential and risks connected with expanding human activity, which directly affect environmental qualities, will rule out the possibility of appropriate and systematic management of these areas. The analysis of green spaces identification, typology and assessment should be combined to form different models of Green Infrastructure. The main purpose of comparing different concepts is to show the sphere of activity of the Green Infrastructure in different conditions. The GI models contribute to long term strategic development goals for data and information management. Analysis and design of emerging Green Infrastructure system take a holistic view which links related physical, environmental, economic, social and cultural aspects of local communities. Planning and design of green system should provide appropriate responses to the distinctive local circumstances.

\section{References}

1. M. Benedict, E. McMahon, Green Infrastructure: Linking Landscapes and Communities. Washington, D.C.: Island Press (2006)

2. A. Zaręba, Problems of Sustainable Development, 9, 149-156 (2014)

3. C.W. Thompson, Landscape and Urban Planning 60 59-72 (2002)

4. G. Bennet, Integrating Biodiversity Conservation and Sustainable Use: Lessons Learned From Ecological Networks, Gland/Cambridge, IUCN (2004)

5. J. Ahern, Landscape and Urban Planning, Special Greenways Issue, 33, 131-155 (1995)

6. www.naturalengland.org.uk (accessed April 26, 2016)

7. https://www.epa.gov/green-infrastructure/benefitsgreen-infrastructure (accessed May 10, 2016)

8. D. C. Rouse, I. F. Bunster-Ossa, Green Infrastructure: A Landscape Approach, American Planning Association, Planning Advisory Service Report Number 571, American Planning Association, (2013)

9. M. Benedict, E. McMahon., Green Infrastructure: Smart Conservation for the 21 st Century, (2001), http://www.sprawlwatc h.org/greeninfrastructure.pdf

10. C.Wayne et al, Ecological Applications, 10, 685-688 (2000)

11.http://www.conservationfund.org/projects/anemerald-necklace-for-los-angeles (accessed April 26, 2016) 12.http://www.trinityrivercorridor.com (accessed April 26, 2016)

13. Regional Plan on Spatial Planning of the Metropolitan Area of Lisbon (Plano Regional de Ordenamento do Território da Área Metropolitana de Lisboa, PROT AML) (2010) http://protaml.inescporto.pt/

14. Maryland's Green Infrastructure Assessment and GreenPrint Program 2004, http://www.conservationfund.org/images/programs/fil es/Marylands_Green_Infrastructure_Assessment_and _Greenprint_Program.pdf(accessed April 26, 2016)

15. $\bar{h}$ ttp://www.greeninfrastructurenw.co.uk/resources/GI guide.pdf (accessed May 10, 2016)

16. W. L. Allen, Journal of Conservation Planning 10, 43 - 51 (2014)

17. http://enviroeconomynorthwest.com/download/envir onmental_quality/projects/A\%20Future\%20for\%20th e\%20Natural\%20Economy.pdf (accessed April 26, 2016) 